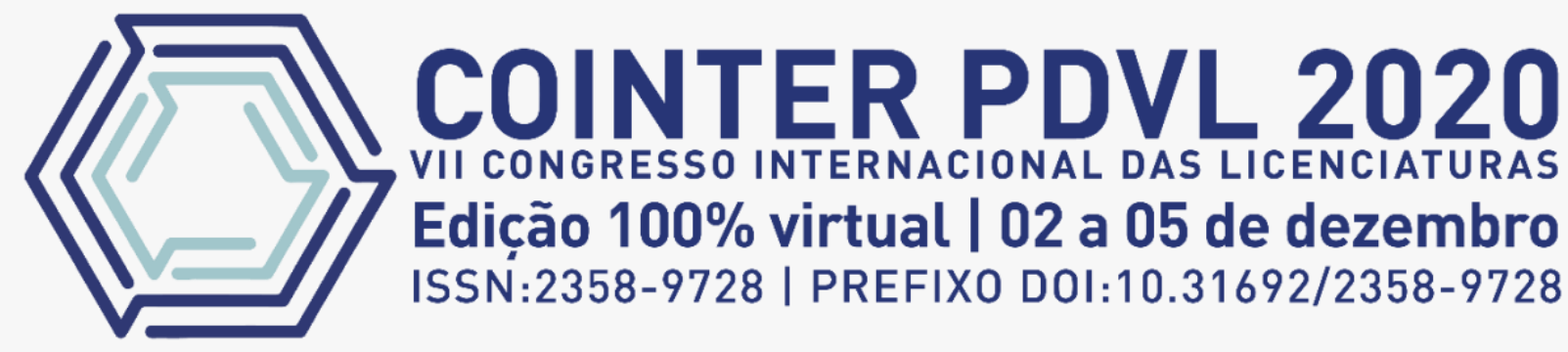

\title{
CONECTAEE: UM SISTEMA PARA FOMENTAR A COMUNICAÇÃO ENTRE OS ATORES ENVOLVIDOS NA EDUCAÇÃO DE ALUNOS COM DEFICIÊNCIA
}

\section{CONECTAEE: UN SISTEMA PARA FOMENTAR LA COMUNICACIÓN ENTRE LOS ACTORES INVOLUCRADOS EN LA EDUCACIÓN DE LOS ESTUDIANTES CON DISCAPACIDADES}

\section{CONECTAEE: A SYSTEM TO FOSTER COMMUNICATION AMONG THE ACTORS INVOLVED IN THE EDUCATION OF STUDENTS WITH DISABILITIES}

\author{
Apresentação: Comunicação Oral
}

Elane Silvino da Silva ${ }^{1}$; Eberson Nascimento Santos ${ }^{2}$; Igor Medeiros Vanderlei ${ }^{3}$; Anderson Fernandes de Alencar ${ }^{4}$; Mariel José Pimentel de Andrade ${ }^{5}$

DOI: https://doi.org/10.31692/2358-9728.VIICOINTERPDVL.0094

\begin{abstract}
RESUMO
Alunos com deficiência, transtornos globais de desenvolvimento ou superdotação têm o direito, previsto na legislação, de receber Atendimento Educacional Especializado em complemento às aulas regulares. Este acompanhamento específico deve ser realizado por professores capacitados, de forma a contribuir no processo educacional, assim como inserção na sociedade. Esta perspectiva, no entanto, desencadeia dificuldades no que se refere a comunicação com outros agentes que estão envolvidos na educação dos discentes, tais como professores do ensino regular, pais ou responsáveis e profissionais de saúde. O marco teórico da pesquisa baseia-se em dois eventos específicos da história da educação inclusiva a Conferência Mundial sobre Educação para Todos de 1990 e a Conferência Mundial de Educação Especial de 1994. Além da leis e decretos que rege a educação especial como a Lei de Diretrizes e Bases da Educação Nacional de 1996 e o decreto n 7.611 de 2011, a relação família e escola é discutida conforme Cavalcante (1998). Assim, esta pesquisa tem como objetivo o desenvolvimento do ConectAEE, que é um sistema de informação Web que busca promover a comunicação desses sujeitos, permitindo o atendimento dos estudantes de forma compartilhada. Para tanto, utilizou-se da metodologia de desenvolvimento de software ágil denominada Scrum, complementada por um estudo bibliográfico. O sistema tem o potencial de se tornar um grande aliado para ações multidisciplinares no contexto da Educação Especial.
\end{abstract}

1 Graduanda do Curso de Licenciatura Plena em Pedagogia da Universidade Federal do Agreste de Pernambuco UFAPE, nane.silvino@gmail.com;

2 Bacharel em Ciência da Computação pela Universidade Federal do Agreste de Pernambuco - UFAPE, eberson.santos1@gmail.com;

3 Professor do curso de Bacharelado em Ciências da Computação pela Universidade Federal do Agreste de Pernambuco - UFAPE, igor.vanderlei@gmail.com;

4 Professor do curso de Licenciatura Plena em Pedagogia pela Universidade Federal do Agreste de Pernambuco UFAPE, anderson.alencar@gmail.com;

5 Professor do curso de Licenciatura Plena em Pedagogia pela Universidade Federal do Agreste de Pernambuco UFAPE, marieljpa@gmail.com. 


\title{
CONECTAEE: UM SISTEMA PARA FOMENTAR A COMUNICAC̨ÃO
}

Palavras-Chave: Atendimento Educacional Especializado, Sistemas de informação Web, Comunicação.

\section{RESUMEN}

Los estudiantes con discapacidades, trastornos del desarrollo global o sobredotación tienen derecho, según lo dispuesto por la ley, a recibir asistencia educativa especializada además de las clases normales. Esta vigilancia específica debe ser realizada por profesores capacitados para contribuir al proceso educativo, así como a la inserción en la sociedad. Esta perspectiva, sin embargo, provoca dificultades en la comunicación con otros agentes que participan en la educación de los estudiantes, como los profesores habituales, los padres o tutores y los profesionales de la salud. El marco teórico de la investigación se basa en dos acontecimientos específicos de la historia de la educación inclusiva: la Conferencia Mundial sobre Educación para Todos de 1990 y la Conferencia Mundial sobre Educación Especial de 1994. Además de las leyes y decretos que rigen la educación especial, como la Ley de Directrices y Fundamentos de la Educación Nacional de 1996 y el Decreto n 7.611 de 2011, la relación entre la familia y la escuela se examina según Cavalcante (1998). Así, esta investigación tiene como objetivo desarrollar la ConectAEE, que es un sistema de información en la Web que busca promover la comunicación de estas materias, permitiendo a los estudiantes asistir de manera compartida. Para ello se utilizó la metodología de desarrollo de software ágil llamada Scrum, complementada con un estudio bibliográfico. El sistema tiene el potencial de convertirse en un gran aliado para las acciones multidisciplinarias en el contexto de la Educación Especial.

Palabras Clave: Servicio Educativo Especializado, Sistemas de Información en la Web, Comunicación.

\begin{abstract}
Students with disabilities, global developmental disorders or over-endowment have the right, provided by law, to receive Specialized Educational Assistance in addition to regular classes. This specific monitoring must be performed by trained teachers in order to contribute to the educational process, as well as insertion into society. This perspective, however, triggers difficulties in communication with other agents who are involved in the education of the students, such as regular teachers, parents or guardians and health professionals. The theoretical framework of the research is based on two specific events in the history of inclusive education the 1990 World Conference on Education for All and the 1994 World Conference on Special Education. In addition to laws and decrees governing special education such as the National Education Guidelines and Basics Act of 1996 and Decree $n^{\circ} .7,611$ of 2011, the relationship between family and school is discussed according to Cavalcante (1998). Thus, this research aims to develop ConectAEE, which is a Web information system that seeks to promote the communication of these subjects, allowing students to attend in a shared way. For this purpose, we used the agile software development methodology called Scrum, complemented by a bibliographic study. The system has the potential to become a great ally for multidisciplinary actions in the context of Special Education.
\end{abstract}

Keywords: Specialized Educational Service, Web Information Systems, Communication.

\section{INTRODUÇÃO}

A Educação Especial desempenha um papel decisivo para a inclusão social, em razão de fazer com que alunos com deficiência sejam capazes de conviver nos mesmos espaços sociais e culturais que outros alunos. Em 1994, ocorreu a Conferência Mundial sobre Educação 
Especial em Salamanca, na Espanha, cujo objetivo foi definir as diretrizes básicas para reformulação dos sistemas educacionais em prol da inclusão. A Conferência deu origem à Declaração de Salamanca, na qual é enfatizada a relevância da Educação Especial quando se afirma que uma pedagogia centrada na criança pode reduzir consideravelmente a taxa de desistência e repetência, garantir índices médios mais altos de rendimento escolar, além de ser benéfico a todos os estudantes e, consequentemente, à sociedade como um todo (UNESCO, 1994).

A Educação Especial é uma área que está sempre se aperfeiçoando, o que é abordado por Maturana e Cia (2015, p. 351) quando informam que "ações, práticas, instrumentos, leis, diretrizes e reformas curriculares têm voltado atenção para respaldar o ambiente escolar e o corpo docente para o recebimento de alunos público-alvo da Educação Especial”. Percebe-se que é imprescindível continuar com este processo com o intuito de contribuir com a ascensão da inclusão escolar, que é um dever moral da nossa sociedade.

Assim como outras áreas, a Educação Especial é beneficiada com contribuições significativas provenientes de Tecnologias da Informação e Comunicação (TIC). Para Gândara (2013), às TIC auxiliam na diminuição das desigualdades e promovem a inclusão escolar e social, além de serem identificadas como uma vantagem para os processos de ensinoaprendizagem dos sujeitos com deficiência, pois possibilitam a comunicação e transmissão de conhecimentos.

Não é de hoje que se sabe que a família tem um papel importante na educação de crianças e adolescentes, pois como Maturana e Cia (2015, p. 350) alegam, a relação famíliaescola "traz implicações para o desenvolvimento social e cognitivo do aluno e está diretamente relacionada ao sucesso escolar". No contexto da Educação Especial, a escola estende-se também ao Atendimento Educacional Especializado (AEE), que deve fazer parte desta relação para garantir os mesmos resultados aos estudantes com deficiência.

Na pesquisa-ação conduzida por Pelosi e Nunes (2011), mostra-se como uma equipe multidisciplinar formada por professores, fonoaudiólogos e terapeutas ocupacionais desenvolveram estratégias de inclusão para alunos com deficiência, fazendo com que eles participassem das aulas de maneira mais ativa e com maior autonomia. Compreende-se assim que o conjunto família-escola, no contexto da Educação Especial, pode receber auxílio de um terceiro componente: a saúde.

Sendo assim, para além do uso das TIC como ferramenta de apoio ao ensinoaprendizagem é imperativo sua utilização como recurso no fomento da relação família-escolasaúde. Um sistema que permita o gerenciamento compartilhado de informações dos estudantes 


\section{CONECTAEE: UM SISTEMA PARA FOMENTAR A COMUNICAC̨ÃO}

da Educação Especial pode potencializar a comunicação entre estes três intervenientes e tornarse uma maneira de alinhar as atividades desempenhadas por profissionais da Educação e da Saúde, beneficiando assim cada indivíduo ao traçar a melhor forma de atender suas necessidades de aprendizagem.

Segundo Moresi (2000, p. 24), “os sistemas de informação têm sido desenvolvidos para otimizar o fluxo de informação relevante no âmbito de uma organização, desencadeando um processo de conhecimento e de tomada de decisão e intervenção na realidade". Assim, parte-se da hipótese que o desenvolvimento e implantação de um sistema de informação Web tem o potencial de ser um instrumento viabilizar uma possível comunicação entre os agentes escola, família e saúde que se relacionam no contexto da Educação Especial.

O trabalho tem por objetivo apresentar o sistema ConectAEE, suas funcionalidades processo de gerenciamento das instituições e dos/as alunos/as, formas de controle de acesso, fórum de discussões entre os usuários, campo para o registro de objetivos de aprendizagem para cada indivíduo e outros recursos de acessibilidade oferecida pelo sistema.

Nas próximas seções é apresentado como trabalho está estruturado. Na primeira seção, é discorrido o marco teórico da pesquisa, no qual é abordado dois eventos que marcaram a história da educação inclusiva conforme Miranda (2008), as leis e decretos que rege a educação especial como a Lei de Diretrizes e Bases da Educação Nacional (BRASIL, 1996) e o decreto n 7.611 de 2011 (BRASIL, 2011), a relação família e escola baseado em Cavalcante (1998).

O processo metodológico é explicitado na segunda seção do trabalho, abordando o tipo de metodologia adotado, os softwares utilizados para desenvolvimento do sistema e a linguagem de programação escolhida.

A terceira seção são apresentados os resultados e discussões da pesquisa, no qual é explanado sobre o sistema desenvolvido e suas principais funcionalidades. Por fim, apresentamos as considerações finais e alguns desafios para ser pensados como possibilidades futuras na melhoria do sistema.

\section{FUNDAMENTAÇÃO TEÓRICA}

Como o desenvolvimento do software ocorreu no âmbito da educação especial, é essencial assinalar algumas especificidades à respeito desta modalidade de ensino que perpassa todos os níveis, etapas e modalidades da educação, assim como as leis e decretos que regulamentam o tema e os sujeitos envolvidos tanto a família, a escola, e profissionais de saúde, isto é, a equipe multidisciplinar. 
Relativo à inclusão, dois eventos são considerados marcos significativos nessa questão por discutirem sobre a viabilização da educação para todos (MIRANDA, 2008). O primeiro evento, em 1990, foi a Conferência Mundial sobre Educação para Todos que foi realizado em Jomtien, Tailândia. Nela foi elaborado o documento intitulado Declaração Mundial sobre Educação para Todos, onde consta que "é preciso tomar medidas que garantam a igualdade de acesso à educação aos portadores de todo e qualquer tipo de deficiência, como parte integrante do sistema educativo" (UNESCO, 1990). O segundo evento, ocorrido em 1994, foi a Conferência Mundial de Educação Especial, em Salamanca, Espanha. A Declaração de Salamanca, resolução concebida nesta Conferência, endossa em âmbito regional, nacional e internacional, princípios, políticas e práticas voltadas a escolarização de todas crianças, independente de suas diferenças.

O Brasil como signatário dessas declarações, assumiu um compromisso, diante da comunidade internacional, de investir na educação inclusiva, de forma a considerar as características únicas dos indivíduos e evitar a exclusão escolar.

Desta forma, através da influência das orientações internacionais e para reforçar a obrigação do País com a educação é sancionada em 1996 a terceira versão da Lei de Diretrizes e Bases da Educação Nacional, lei n ${ }^{\circ}$ 9.394, ainda em vigor atualmente. O capítulo V desta Lei discorre especificamente sobre a Educação Especial e seu conteúdo trouxe avanços significativos. Para exemplificar, tem-se a oferta da educação especial ao início da educação infantil, na faixa etária de zero a seis anos e a garantia de professores para atendimento especializado, bem como professores do ensino regular, capacitados para atender à diversidade dos educandos (BRASIL, 1996).

O decreto $n^{\circ} 7.611$ de 2011 fala sobre a educação especial, o atendimento educacional especializado e outra providências, nos artigos segundo e terceiro são especificados o públicoalvo, que abrange mais do que as pessoas com deficiência, e os objetivos do atendimento:

Art. $2^{\circ}$ A educação especial deve garantir os serviços de apoio especializado voltado a eliminar as barreiras que possam obstruir o processo de escolarização de estudantes com deficiência, transtornos globais do desenvolvimento e altas habilidades ou superdotação. [...] Art. $3^{\circ}$ São objetivos do atendimento educacional especializado: I - prover condições de acesso, participação e aprendizagem no ensino regular e garantir serviços de apoio especializados de acordo com as necessidades individuais dos estudantes; II - garantir a transversalidade das ações da educação especial no ensino regular; III - fomentar o desenvolvimento de recursos didáticos e pedagógicos que eliminem as barreiras no processo de ensino e aprendizagem; e IV - assegurar condições para a continuidade de estudos nos demais níveis, etapas e modalidades de ensino (BRASIL, 2011). 


\section{CONECTAEE: UM SISTEMA PARA FOMENTAR A COMUNICAC̨ÃO}

Pode-se notar que, de modo geral, o propósito do AEE é providenciar meios de incluir os atendidos no ambiente educacional. Nesse sentido, Vilaronga e Mendes (2014) indicam que os educadores que trabalham individualmente nas salas de aula regulares sentem dificuldade para realizar ações pedagógicas de qualidade para estes estudantes. Assim, para que o modelo inclusivo funcione, de fato, é necessário que haja um ensino colaborativo entre os professores das duas modalidades de ensino, de forma que eles estejam em sintonia para planejar e instruir ações para um grupo heterogêneo de estudantes.

A Educação Especial, na perspectiva da educação inclusiva, necessita de mais profissionais do que aqueles envolvidos na esfera pedagógica. Nesse aspecto, Pelosi e Nunes (2011) estabelecem que é válida a existência de uma rede de apoio composta por sujeitos que possam compartilhar métodos, técnicas e atividades que favoreçam o sucesso de professores e alunos.

Neste seguimento, a área da Saúde contém a maior quantidade de profissionais que podem contribuir com a Educação Especial. Na pesquisa conduzida por Silva, Molero e Roman (2016, p.111), os professores "manifestaram interesse em compreender o aluno do ponto de vista clínico, visando adequação de métodos, materiais e conteúdos no campo pedagógico". Isso demonstra o quanto se faz necessário para os professores conhecerem, através de outro ângulo, os progressos e dificuldades de seus alunos e assim poderem traçar uma estratégia educacional adequada.

A literatura mostra que a colaboração entre a escola e a família resulta em benefícios não somente para os alunos, como também para os pais/responsáveis e para a escola. Segundo Polonia e Dessen (2005, p. 305), aos alunos é concedida uma evolução "nos níveis cognitivos, afetivos, sociais e de personalidade", o que pode dar mais significado a experiência educacional deles. Relativo aos pais e a escola, Cavalcante (1998) sinaliza que eles se tornam mais ativos na comunidade e tendem a melhorar o contato com os filhos, enquanto que para ela há a redução dos conflitos com os familiares e a melhora do ambiente escolar.

Alguns obstáculos são identificados por Cavalcante (1998) no que se refere a existência de uma simbiose entre família e escola. Do ponto de vista dos pais, a ausência de recursos, como meios de transporte e creches, além de problemas para saírem do trabalho para se envolverem nas atividades escolares são fatores que contribuem negativamente. Para os professores, um dos problemas incide na limitação de tempo disponível para que possam se comunicar. Nesse ponto, destaca-se a importância de prover soluções que minimizem estes obstáculos e que simplifiquem o processo de comunicação entre a escola e a família. 


\section{METODOLOGIA}

Diante das características deste projeto, optou-se pelo uso da metodologia ágil denominada Scrum. Tal metodologia funciona de forma incremental e iterativa, uma vez que o software ou produto é construído através de subconjuntos independentes de funcionalidades e seu progresso e refinamento é realizado de forma sucessiva. Além disso, são aplicados vários artefatos, eventos, papéis e regras que são utilizados no gerenciamento de projetos de diferentes áreas do conhecimento.

Para a confecção do protótipo, foi utilizado o Balsamiq Cloud 1, que é uma ferramenta gráfica para esboçar interfaces de usuário de sites e sistemas para diferentes plataformas. A ferramenta permite a construção de wireframes, que auxiliam no entendimento do fluxo das informações e a manter o foco na estrutura, fornecendo interatividade suficiente para facilitar a colaboração e obtenção de avaliações dos usuários sobre o design proposto (BALSAMIQ STUDIOS, LLC, 2019).

O segundo passo na fase de consolidação do software concentrou-se na modelagem do banco de dados. Para tal, levou-se em consideração que um modelo de dados de alto nível, ou conceitual, fornece uma estrutura na qual se pode especificar, de modo sistemático, as necessidades de dados dos usuários (SILBERSCHATZ; SUNDARSHAN; KORTH, 2012).

Com a estruturação do sistema definida, partiu-se para seu desenvolvimento. Foi decidido que o projeto em questão seria feito para Web devido à necessidade de manter os dados gerados centralizados e, principalmente, à mobilidade e portabilidade proporcionada, uma vez que é possível acessar remotamente às informações através de diferentes aparelhos, como computadores e smartphones, conectados à internet.

A linguagem de programação escolhida para o desenvolvimento foi o PHP, por ser uma linguagem popular de uso geral, rápida, flexível e pragmática, especialmente adequada ao desenvolvimento da Web (THE PHP GROUP, 2001). O framework PHP utilizado foi o Laravel, que é de código aberto e se destaca por fornecer código e recursos concisos que auxiliam os desenvolvedores a escreverem de forma rápida, códigos simples, claros, duradouros e de fácil manutenção (STAUFFER, 2019).

\section{RESULTADOS E DISCUSSÃO}

No decorrer do trabalho é apresentado o sistema ConectAEE, suas principais funcionalidades. Ao final são expostas as considerações finais e desafios a serem pensados ou melhoradas no sistema criado. 


\section{CONECTAEE: UM SISTEMA PARA FOMENTAR A COMUNICAC̨ÃO}

\section{O sistema ConectAEE}

O principal intuito do ConectAEE é promover a comunicação entre professores do ensino regular e especial, familiares e outros profissionais que prestem qualquer tipo de atendimento ao aluno com deficiência, fornecendo subsídios importantes para, potencialmente, tornar o processo de ensino multidisciplinar e compartilhado.

Para tanto, a ferramenta possibilita o registro e compartilhamento dos dados de um aluno e das ações propostas para o seu atendimento, sejam elas de cunho pedagógico ou clínico, apenas para usuários autorizados. Dessa maneira, o artefato permite que os usuários explorem conhecimentos específicos de outros profissionais, além de conferirem os progressos que os discentes alcançam em outros ambientes.

O ConectAEE é um sistema de informação Web, livre e gratuito que foi projetado para o uso da comunidade. Seu código-fonte está disponível no link https://github.com/EbersonSantos/ConectAEE e ele pode ser acessado através do endereço http://app.uag.ufrpe.br/conectaee. Na Imagem 1, é apresentada a interface inicial do sistema.

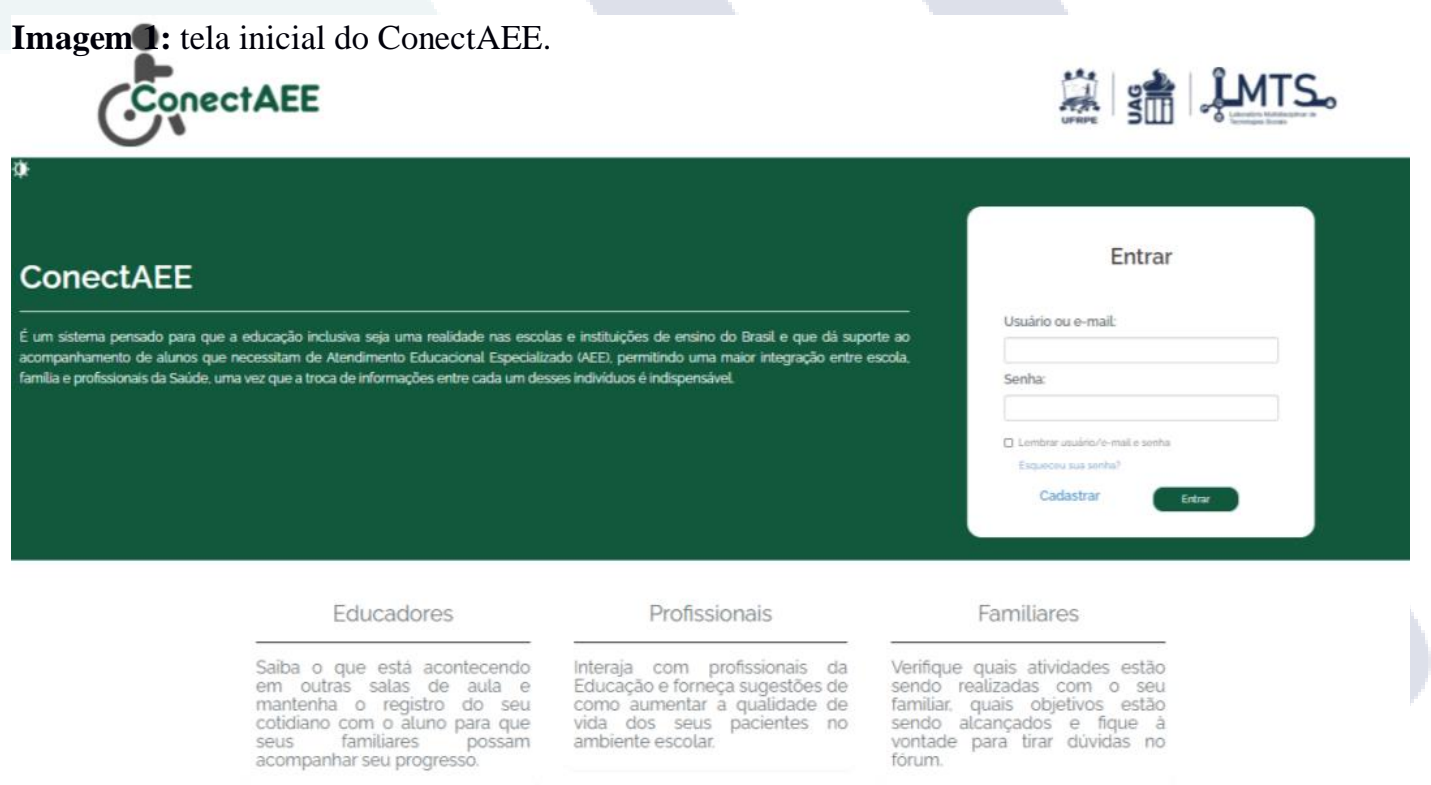

Fonte: Própria (2019)

\section{Algumas funcionalidades encontradas no software}

Para que o sistema possa ser acessado e suas funcionalidades utilizadas é necessário que o usuário se cadastre na plataforma. Para isso ele deve fazer o preenchimento de um formulário, onde são solicitados alguns dados pessoais, além do nome de usuário e uma senha, posteriormente usados para fazer login. 
Após o processo de login, o usuário pode usufruir das funcionalidades que o ConectAEE apresenta e que são descritos nas próximas linhas.

\section{Gerenciamento de instituições}

O ConectAEE permite que um usuário faça o gerenciamento de múltiplas instituições, Imagem 2, que podem ser atreladas posteriormente a um aluno no momento de seu cadastramento.

Imagem 2: Interface para gerenciamento de instituições

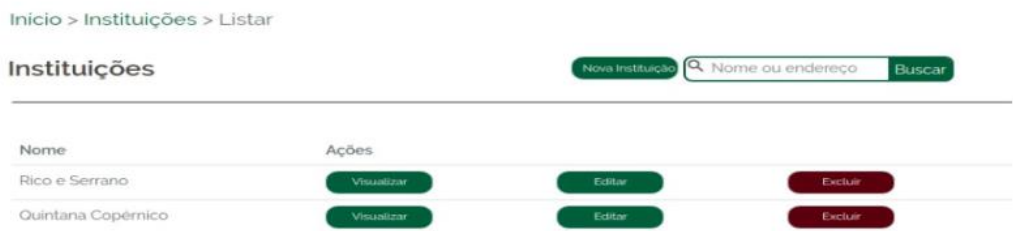

Fonte: Própria (2019).

O cadastro de mais de uma instituição foi implementado como abstração do contexto do mundo real, uma vez que os alunos da Educação Especial podem estar alocados, em turnos diferentes, em mais de uma instituição de ensino e professores podem trabalhar em mais de uma escola.

Além do cadastro, outras operações fundamentais como listagem, busca, edição e exclusão de instituições também foram implementadas.

\section{Gerenciamento de alunos}

Para utilizar o sistema, de fato, é necessário fazer o cadastro de alunos. O sistema exige que o usuário tenha cadastrado, pelo menos, uma instituição antes de prosseguir para tal funcionalidade.

O usuário deve informar o CPF do aluno para que seja feita uma busca prévia no sistema com o intuito de impedir registros duplicados. Após ser confirmado que o CPF informado não está registrado, o sistema redireciona para a página de cadastro de alunos, do contrário pode ser requisitada autorização para acessar o perfil já inserido. 


\section{CONECTAEE: UM SISTEMA PARA FOMENTAR A COMUNICAC̨ÃO}

Para facilitar o preenchimento, o formulário é dividido em seis segmentos, sendo eles: instituição, identificação, endereço, dados médicos, observações e perfil do cadastrante, como mostrado na Imagem 3.

Imagem 3: Formulário para cadastro de alunos

Novo Aluno
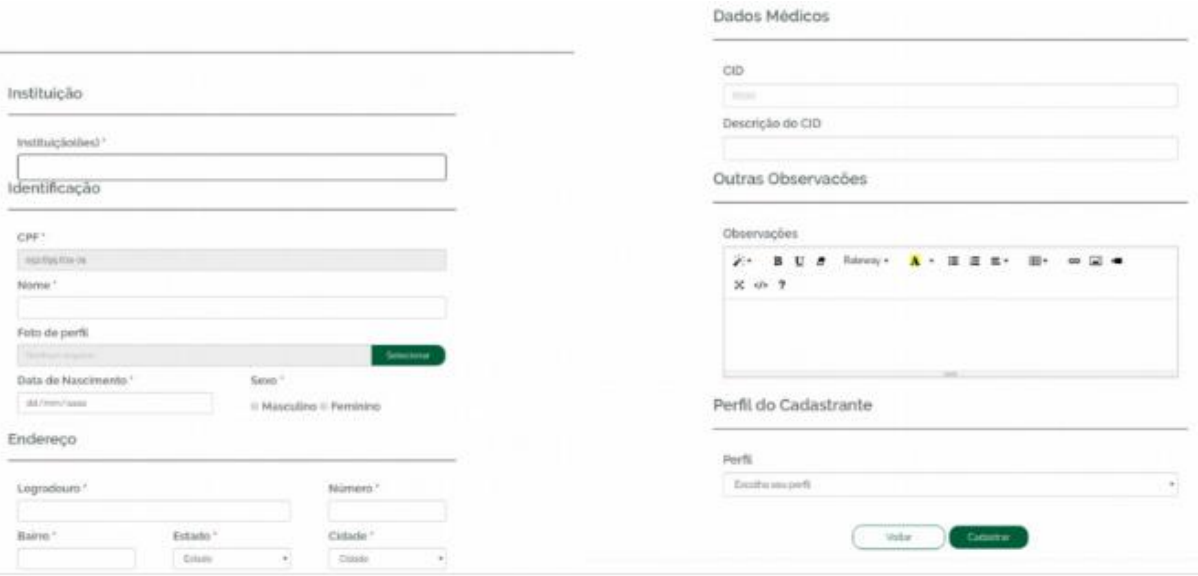

Fonte: Própria (2019).

A finalidade do campo observações é manter um campo livre onde possam ser registradas outras informações pertinentes sobre o aluno, tais como comportamento, medicamentos etc.

O usuário que faz o cadastro de um aluno, precisa informar no segmento "Perfil do Cadastrante" se ele é o responsável por aquele aluno ou se ele é um professor de Atendimento Educacional Especializado. Caso a segunda opção seja escolhida, é necessário informar o nome de um novo usuário ou inserir um usuário já existente para ser o responsável pelo aluno, com o intuito de que ele também tenha acesso ao perfil do discente.

Após o cadastro ser finalizado, é possível visitar a página do perfil do aluno e acessar outras funcionalidades. Na Imagem 4 é apresentado dados fictícios para o perfil de um aluno, sendo a foto presente na figura retirada do site Pixabay e borrada para preservar a identidade do garoto. 
Imagem 4: Interface para gerenciamento de aluno

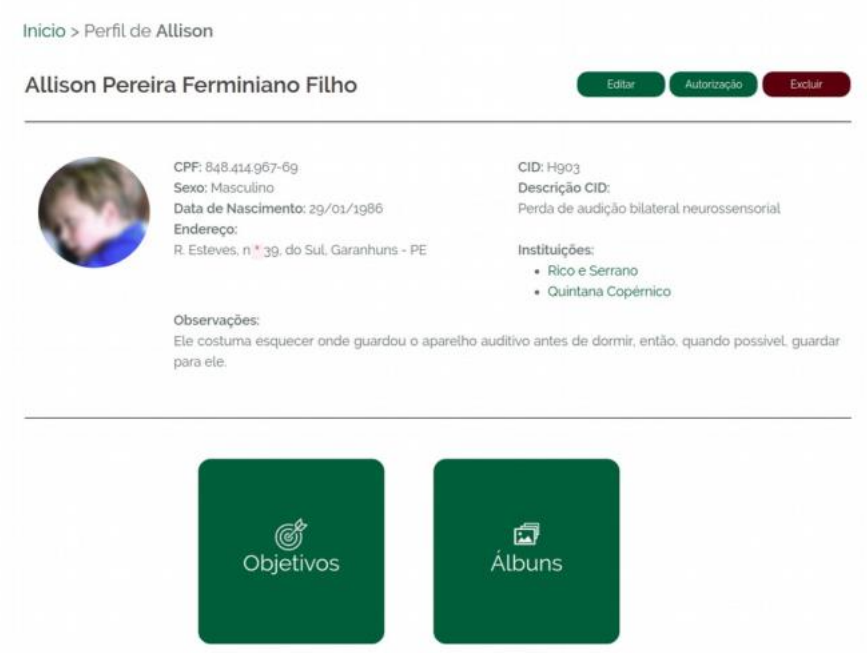

Fonte: Própria (2019)

Para realizar o gerenciamento dos alunos, além do cadastro, outras funcionalidades essenciais também foram desenvolvidas, tais como listagem, busca, edição e remoção.

\section{Controle de acesso do/a aluno/a cadastrado}

O usuário que cadastrar um aluno, assim como o usuário que representa seu responsável se tornam automaticamente administradores do perfil registrado. Uma das funcionalidades que estes administradores adquirem é o controle sobre quem pode acessar este perfil.

Assim, é possível autorizar o acesso para outros usuários, como professores do ensino regular, profissionais de saúde e outros responsáveis, inclusive podendo torná-los administradores também. Se um profissional parar de prestar atendimento ao aluno, também é possível revogar seu acesso. A Imagem 5 representa a interface do sistema no que diz respeito às autorizações de acesso. 


\section{CONECTAEE: UM SISTEMA PARA FOMENTAR A COMUNICAC̨ÃO}

Imagem 5: Interface para controle de acesso ao perfil de aluno

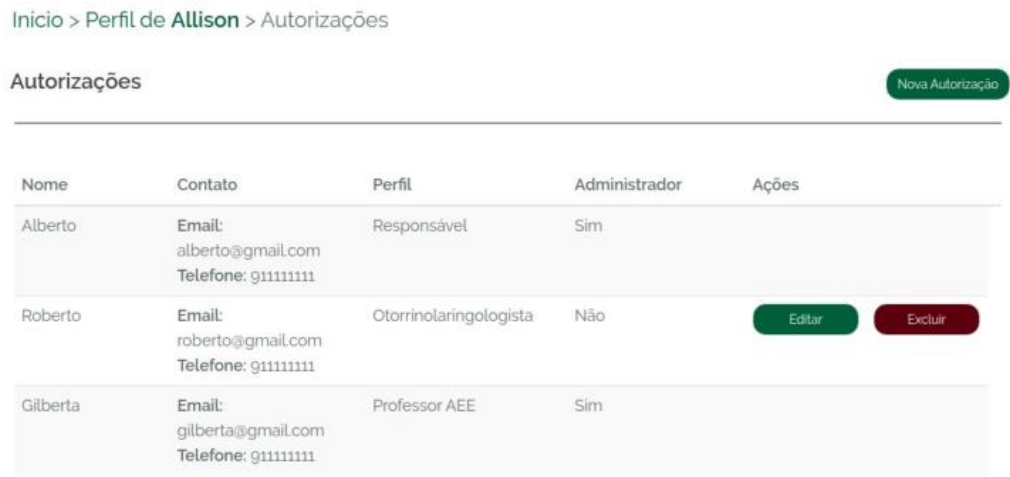

Fonte: Própria (2019)

\section{Outras possibilidades de comunicação}

O ConectAEE conta com um canal de comunicação específico para cada aluno cadastrado, apresentado na Imagem 6. Esse espaço, intitulado fórum, proporciona a todos os atores que possuem acesso ao perfil de um aluno, uma maneira prática para interagirem livremente ao enviar mensagens multimídia que podem conter, por exemplo, textos, imagens, vídeos e links.

Imagem 6: Fórum de um aluno

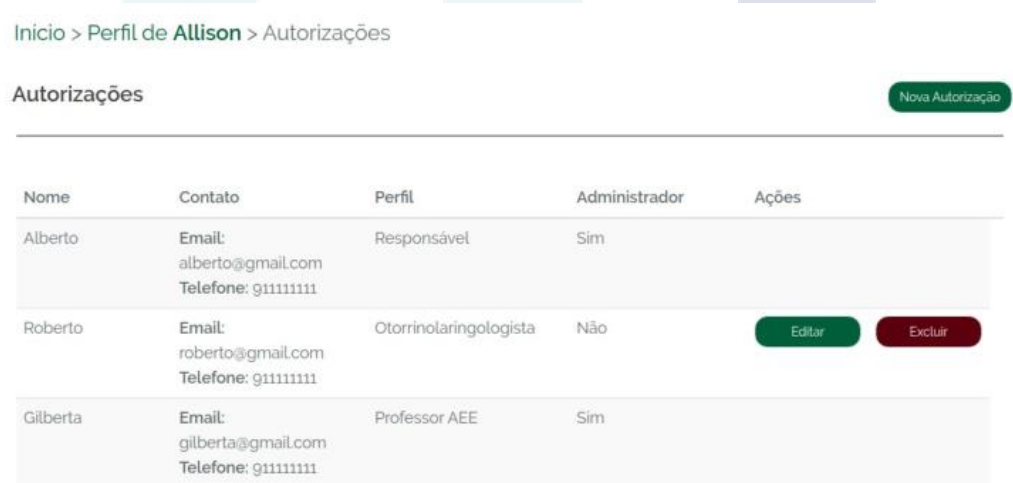

Fonte: Própria (2019)

Os casos em que esse recurso pode ser usado são diversos, já que os usuários podem deixar recados, esclarecer dúvidas, consultar outros sujeitos, pedir opiniões e assim por diante.

\section{Acompanhamento por meio dos objetivos}

A principal funcionalidade implementada diz respeito ao registro e gerenciamento dos objetivos almejados para os alunos. O sistema possibilita a qualquer educador ou profissional 
de saúde, que tenha acesso ao perfil de um aluno, descrever e atribuir objetivos educacionais ou relativos a saúde para ele. Tais objetivos ficam disponíveis para serem consultados tanto por esses indivíduos, quanto pelos responsáveis pelo aluno. Como exemplo, a Imagem 7 apresenta objetivos criados por dois tipos de usuários diferentes.

Imagem 7: Objetivos para um aluno e especificações sobre ele

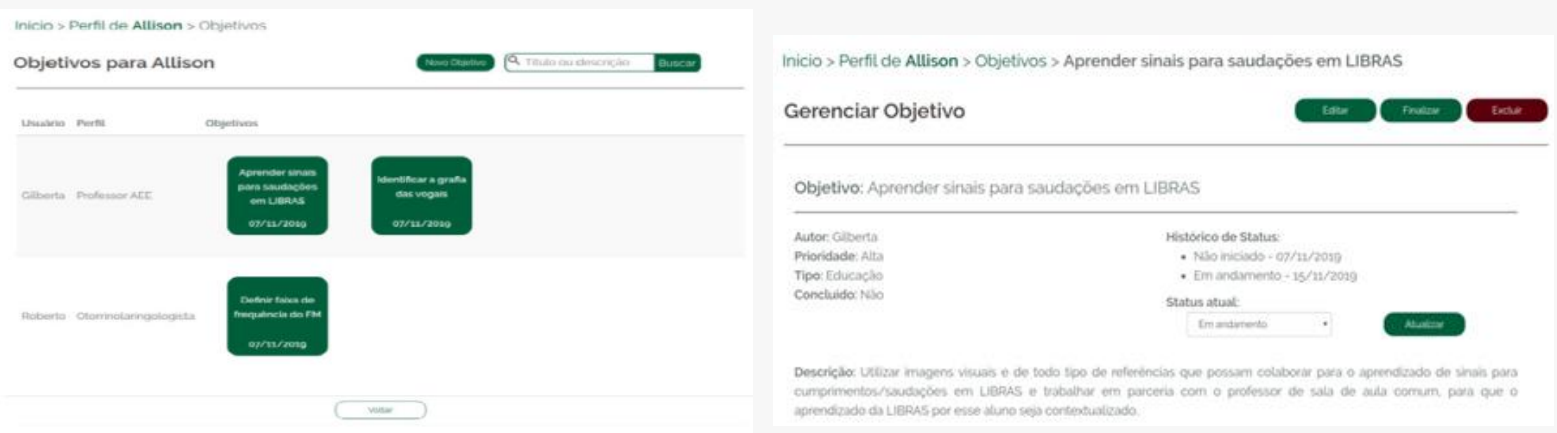

Fonte: Própria (2019)

Ao explorar o conteúdo de um objetivo, os visitantes podem se apoderar de outras informações a respeito dele, tais como descrição, prioridade e o histórico da situação dele (em andamento, em pausa, cancelado e outros), bem como editar, excluir e finalizar, isto é, definilo como concluído.

Além de definir o objetivo, quem o cadastra pode planejar as atividades que serão desenvolvidas para atingi-lo. Tais atividades podem ser consideradas como metas que possuem um escopo menor e mais simples e culminarão na realização do objetivo.

De posse do conhecimento dos objetivos e atividades, outros atores podem dar ênfase no conteúdo que está sendo trabalhado. Por exemplo: se o professor AEE está ensinando ao aluno o sinal para “bom dia!” em LIBRAS, todas as manhãs os pais da criança podem reproduzir este sinal para reforçar sua aprendizagem.

As atividades possuem como característica um status (não iniciada, em andamento e finalizada) que auxilia a mensurar o progresso de realização do objetivo. Dessa forma, os pais ou responsáveis, assim como outros profissionais podem acompanhar o andamento do objetivo e saber o que já foi realizado com o aluno.

Para estimular a participação multidisciplinar da equipe que acessa o perfil de um aluno, cada usuário pode fazer sugestões de atividades para aquele objetivo, baseados em suas próprias experiências e conhecimentos específicos.

Para facilitar a comunicação, ao averiguar os detalhes de uma sugestão, os usuários podem deixar comentários com o propósito de discutir sobre a proposta estabelecida. O intuito 


\section{CONECTAEE: UM SISTEMA PARA FOMENTAR A COMUNICAC̨ÃO}

de dispor objetivos, atividades e sugestões de maneira compartilhada é trazer transparência quanto ao planejamento individual feito para os estudantes nos diversos ambientes diferentes que ele pode frequentar. Além disso, é possível manter um histórico dos atendimentos já realizados por profissionais diversos que pode ser consultado a qualquer momento. Por fim, todos podem acompanhar e contribuir com o desenvolvimento do aluno, alcançando, potencialmente, melhores resultados.

\section{Recursos de acessibilidade na plataforma}

A leitura e compreensão do conteúdo, por parte de seu público-alvo, é essencial para garantir o sucesso na utilização do software, por isso foram consideradas medidas para melhorar sua acessibilidade.

O modo de alto-contraste, implementado no sistema beneficia indivíduos com baixa visão ou com a visão comprometida pela idade e pode melhorar a experiência destes ao utilizar o ConectAEE.

De modo semelhante, a ferramenta VLibras foi utilizada para que pessoas surdas possam interagir, sem barreiras, com o ConectAEE. O VLibras é responsável por tornar diversas plataformas acessíveis através da tradução automática de conteúdos digitais do Português para a LIBRAS (MINISTÉRIO DA ECONOMIA, [s.d.]).

\section{CONCLUSÕES}

A literatura mostra que há um problema na comunicação entre os diversos agentes envolvidos no contexto da Educação Especial, ou seja, professores (ensinos regular e especial), profissionais da área da Saúde e pais/responsáveis. Apesar da atuação de uma equipe multidisciplinar causar efeitos positivos na aprendizagem de pessoas com deficiência, fatores como distância e tempo impedem este processo.

A inserção das TIC neste cenário tem potencial para se tornar um forte aliado no auxílio e estímulo das práticas pedagógicas e clínicas conjuntas, beneficiando, consequentemente aos alunos/pacientes em questão.

A discussão acerca da versão apresentada do sistema de suporte ao acompanhamento de alunos que necessitam de Atendimento Educacional Especializado (AEE), revelou a perspectiva de trabalhos futuros para o desenvolvimento de versões subsequentes.

Um dos pontos para atualização refere-se à inserção das instituições de ensino como usuários que podem fazer o cadastramento dos professores da plataforma, de forma que a identidade destes possam ser confirmadas. Outra sugestão é a emissão de relatórios que possam 
ser emitidos por órgãos governamentais, como Secretarias de Educação, que necessitam quantificar dados sobre a Educação Especial dos municípios.

Com base no que foi apresentado, a realização de um estudo de caso onde o ConectAEE seja implantado em uma instituição de ensino é de grande importância para constatar os benefícios de sua utilização e condicionar ao uso ininterrupto do sistema.

\section{REFERÊNCIAS}

BALSAMIQ STUDIOS, LLC. What tools does Balsamiq offer to help rid the world of bad software?. Disponível em: https://balsamiq.com/company/\#whatis. Acesso em: 12 out. 2019.

BRASIL. Decreto $\mathbf{n}^{\circ}$ 7.611. Dispõe sobre a educação especial, o atendimento educacional especializado e dá outras providências, 17 nov. 2011. Disponível em: http://www.planalto.gov.br/ccivil_03/_Ato2011-2014/2011/Decreto/D7611.htm. Acesso em: 23 nov. 2019.

BRASIL. Lei no 9.394. Estabelece as diretrizes e bases da educação nacional, 20 dez. 1996. Disponível em: http://www.planalto.gov.br/ccivil_03/leis/19394.htm. Acesso em: 26 out. 2019

CAVALCANTE, R. S. C. Colaboração entre pais e escola: educação abrangente. Psicologia Escolar e Educacional, v. 2, n. 2, p. 153-160, 1998.

GÂNDARA, R. I. V. A utilização das TIC como meio de aprendizagem na Educação Especial. Lisboa: Escola Superior de Educação João de Deus, jul. 2013.

MATURANA, A. P. P. M.; CIA, F. Educação Especial e a Relação Família - Escola: Análise da produção científica de teses e dissertações. Psicologia Escolar e Educacional, v. 19, p. 349$358,2015$.

MINISTÉRIO DA ECONOMIA. SECRETARIA DE GOVERNO DIGITAL. VLibras. Disponível em: https://www.vlibras.gov.br/. Acesso em: 16 nov. 2019.

MIRANDA, A. A. B. Educação Especial no Brasil: Desenvolvimento Histórico. Cadernos de História da Educação, v. 7, p. 29-44, 2008.

MORESI, E. A. D. Delineando o valor do sistema de informação de uma organização. Ciência da Informação, v. 29, n. 1, p. 14-24, abr. 2000.

PELOSI, M. B.; NUNES, L. R. D. DE P. A ação conjunta dos profissionais da saúde e da educação na escola inclusiva. Revista de Terapia Ocupacional da Universidade de São Paulo, v. 22, n. 1, 1 abr. 2011.

POLONIA, A. DA C.; DESSEN, M. A. Em busca de uma compreensão das relações entre família e escola. Psicologia Escolar e Educacional, v. 9, n. 2, 2005.

SILBERSCHATZ, A.; SUNDARSHAN, S.; KORTH, H. F. Sistema de banco de dados. Tradução Daniel Vieira. 6. ed. Rio de Janeiro: Elsevier, 2012. 
SILVA, C. C. B. DA; MOLERO, E. S. DA S.; ROMAN, M. D. A Interface entre Saúde e Educação: percepções de educadores sobre educação inclusiva. Psicologia Escolar e Educacional, v. 20, n. 1, p. 109-115, 2016.

STAUFFER, M. Laravel: Up \& Running: A Framework for Building Modern PHP Apps. Sebastopol, CA: O’Reilly Media, 2019.

THE PHP GROUP. PHP: Hypertext Preprocessor. Disponível em: https://www.php.net/. Acesso em: 25 set. 2019.

UNESCO. Declaração Mundial sobre Educação para Todos, 1990. Disponível em: https://unesdoc.unesco.org/ark:/48223/pf0000086291_por/PDF/086291por.pdf.multi. Acesso em: 26 out. 2019.

UNESCO. Declaração de Salamanca, 1994. Disponível em: http://portal.mec.gov.br/seesp/arquivos/pdf/salamanca.pdf. Acesso em: 26 ago. 2019

VILARONGA, C. A. R.; MENDES, E. G. Ensino colaborativo para o apoio à inclusão escolar: práticas colaborativas entre os professores. Revista Brasileira de Estudos Pedagógicos, v. 95, n. 239, p. 139-151, abr. 2014. 